\title{
Clinical leadership - are clinicians up for it?
}

\author{
Author: Peter Lees ${ }^{\mathrm{A}}$
}

The knee jerk reaction is yes, of course, doctors have been leading for centuries. Closer exploration of the question, however, gives a less certain response. By up for it, do we mean willing, able or both?

Reluctance by doctors to engage in management and leadership at other than the clinical team level is prevalent. There are disproportionately fewer medical chief executives compared with other clinical professions and compared with many other countries. Medical leadership as a career is neither widely respected nor popular within the profession; few doctors in senior leadership positions will enthuse about the support they get from clinical colleagues despite the increasing challenges of such jobs and their potential to ensure the medical voice is heard at the highest levels. Despite this, coffee rooms across the land echo to the bemoaning of the reduction in influence of doctors. With selective memory, many look back unfavourably on the introduction of general management following the 1983 Griffiths report to the Thatcher government. It is widely believed that this heralded the ceding of power to managers but this conveniently forgets Griffiths' other exhortation: 'The nearer that the management process gets to the patient, the more important it becomes for the doctors to be looked upon as the natural managers'. The profession faces the uncomfortable fact that it has been complicit in any loss of influence.

Regardless of why doctors are under-represented in healthcare leadership, if the end result is disengagement and unhappiness, there is a pressing need to reverse this. Unhappy staff are (much) less productive than happy staff ${ }^{1}$ and the collective disengagement of doctors in an organisation is not good for patients. Medical engagement within organisations can now be measured and there is a positive association with quality as adjudged by the Care Quality Commission. ${ }^{2}$ The responsibility to address this lies both within the profession and in the employing organisations, perhaps even government. In a cashlimited system, even the most cynical should recognise that an engaged and content medical workforce has major benefits beyond decent human resources practice and, to put it bluntly, they should do something about it.

It would be ridiculous to argue that doctors cannot lead - proving they can is another matter. To verify clinical

Author: ${ }^{A}$ chief executive and medical director, Faculty of Medical Leadership and Management, London, UK competence doctors can draw on professional qualifications, appraisal, audit and research. In the face of this noble obsession with clinical standards, it is surprising that, until this year, we have had no benchmarks for medical leadership or management despite the existence of large numbers of medical leadership roles carrying major responsibilities and consequences. In February, the intercollegiate Faculty of Medical Leadership and Management published the first Leadership and management standards for medical professionals ${ }^{3}$ following widespread consultation. These offer a benchmark for self-assessment and a set of standards against which individuals and organisations can assess and appraise medical leaders. In addition, a multiple level medical leadership $360^{\circ}$ feedback tool is at the pilot stage, and a multiple-level certification process will be launched in 2016.

Standards should also inform training and development another area in which medicine excels clinically, while lagging behind with respect to leadership and management. The myth of the born leader forging forward on native wit alone is long $\operatorname{dead}^{4}$ and all can enhance their leadership skills; however quality evidence about what to offer and when is poor. ${ }^{5}$ Clinical training and education has been honed over centuries, is highly organised and highly regulated. Leadership and management training boasts none of those laudable features, although progress has been made over the past decade. There is a need to systematically recognise that all doctors lead from the day they start to practise clinically and that with increasing seniority they lead more, with some making leadership a profession. The military develops leadership from day one; medicine must do the same and be proficient in succession planning and clearer about career structures and opportunities.

Some regard leadership as the latest fad, soon to pass, but that is to ignore the growing body of evidence showing the positive impact of good leadership on clinical care. ${ }^{6,7} \mathrm{We}$ live in challenging times where the demands for improving quality compete with savage demands for saving money. Good leadership creates a virtuous circle which per se is largely unrecognised and untapped. In the face of this evidence, are we negligent as a system and as a profession in not focusing on the systematic development of medical leadership? It is time to drop the immature references to going over to the dark side and time to start respecting excellence in medical leadership every bit as much as we respect excellence in clinical practice and academia. To do so will surely contribute positively to maintaining the UK 
healthcare systems among the best in the world and better equip a highly able workforce to conquer the relentless challenge posed by the advancement of medicine, public expectation and affordability.

\section{References}

1 Oswald AJ, Proto E, Sgroi D. Happiness and productivity. Warwick: University of Warwick, 2014. Available online at www2.warwick. ac.uk/fac/soc/economics/staff/eproto/workingpapers/happinessproductivity.pdf [Accessed 9 November 2015].

2 Spurgeon P, Barwell F, Mazelan P. Developing a medical engagement scale (MES). Int J Clin Leadersh 2008;16:213-23.

3 Faculty of Medical Leadership and Management. Leadership and management standards for medical professionals. London: FMLM, 2014. Available online at www.fmlm.ac.uk/leadership-and-management-standards-for-medical-professionals [Accessed 9 November 2015].
4 The King's Fund. The future of leadership and management in the NHS. No more heroes. London, The King's Fund, 2011. Available online at www.kingsfund.org.uk/sites/files/kf/future-of-leadershipand-management-nhs-may-2011-kings-fund.pdf [Accessed 9 November 2015]

5 West M, Armit K, Loewenthal L et al. Leadership and leadership development in healthcare: the evidence base. London: FMLM, 2015.

6 West MA, Borrill C, Dawson J et al. The link between the management of employees and patient mortality in acute hospitals. Int $J$ Hum Resour Manag 2002;13:1299-310.

7 Shipton H, Armstrong C, West M, Dawson J. The impact of leadership and quality climate on hospital performance. Int J Qual Health Care 2008; 20:439-45.

Address for correspondence: Mr P Lees, Faculty of Medical Leadership and Management, 2nd Floor, 6 St Andrews Place, London NW1 4LB, UK.

Email: peter.lees@fmlm.ac.uk

\section{College Day Monday 21 March 2016}

The Royal College of Physicians combines the annual general meeting of fellows with the presidential election and a programme of lectures likely to be of interest to fellows, members and the general public.

For full details visit: www.rcplondon.ac.uk/events
Fitzpatrick Lecture Churchill's medical men Dr David Eedy, president, British Association of Dermatologists

\section{Samuel Gee Lecture}

Treating COPD: against all odds Professor Wisia Wedzicha, Imperial College London 